\title{
The Inequality-Adjusted Human Development Index: A Constructive Proposal
}

\author{
DOUGLAS A. HICKS* \\ Harvard University, Cambridge, Massachusetts, U.S.A.
}

\begin{abstract}
Summary. - This paper proposes a method to incorporate a concern for distributional inequalities of income, education, and longevity into the framework of the Human Development Index (HDI), as it is presently designed by the United Nations Development Programme. The paper constructs Gini coefficients, for a set of 20 developing countries, measuring inequalities in annal incone, educational attainment, and life-span attainment. These calculations are combined with data from the HDI to produce an Inequality-Adjusted Human Development Index (IAHDI). The implications of this proposed index for evaluating and promoting development are considered. (C) 1997 Elsevier Science Ltd
\end{abstract}

Key words - inequality, development, distribution, index, Gini coefficient, Sen

\section{INTRODUCTION}

Seeking to "put people back at the center of development," the UNDP Human Development Reports (UNDP, 1990, 1991, 1992, 1993, 1994, 1995, 1996) have helped expand the focus of economic development to include wider questions of human well-being and quality of life. The very choice of the socioeconomic indicators incorporated into the Human Development Index (HDI) - adult literacy rates, educational enrollment ratios, and life expectancy at birth, as well as a specially adjusted income-per-capita measure-was intended to illuminate the significant deficiencies of resources and opportunities for a large proportion of the world's population. As a supplement to income-based development measures such as GNP per capita, the HDI was designed to reflect the impact of economic output and growth on various dimensions of people's lives.

In dimensions of life such as income, education, and health/longevity, inequality is significant for economic and ethical analyses. "Relative" deprivations resulting from inequalities are distinct from (though related to) "absolute" deprivations; thus alongside knowing a society's total or average endowment of particular gonds like income, education, and healthcare, information can also be obtained about the distribution of those goods across the population.

Yet inequality, like the more foundational idea equality, remains a complex and elusive concept for assessing well-being and development. While the collaborators of the Human Development Reports have estimated inequalities of income in one Report (1993), ${ }^{1}$ no measure has yet attempted to consider directly the distributional inequalities within the other two dimensions comprising the Human Development Index-education and health/longevity. ${ }^{2}$

This paper is an attempt to do just that-to offer an Inequality-Adjusted Human Development Index, or IAHDI. My proposal involves conceptualizing and then estimating inequality measures in all three dimensions considered in the Human Development Index-income, education, and health/longevity. To these ends, the paper proceeds in the following way. Section 2 considers the concept of "inequality" and its relevance-and complexities-for considerations of economic development and human well-being. Section 3 reviews the concept of human development and the formulation of the Human Development Index. Section 4 explores distributional shortcomings of the HDI in its present form and some alternative approaches to addressing these deficiencies. In Section 5, issues of conceptualizing and measuring inequality in the "spaces" of income, education, and health/longevity are taken up, with particular attention paid to the Gini coefficient as a viable index of inequality in these spaces.

Section 6 presents my empirical attempt to

*I would like to thank Amartya Sen, Stephen Marglin, Paul Streeten, David Hollenbach, and Ronald Thiemann for their careful, constructive comments on this paper. Final revision accepted: March 4, 1997. 
estimate Gini coefficients for income, education, and longevity for 20 developing countries for which recent and relevant data are available. The benefits as well as the limitations of these measures are discussed. Section 7 proposes combining these three inequality indices with information presently reflected in the HDI to derive an Inequality-Adjusted Human Development Index.

The scope of this essay, then, ranges from the conceptualization of inequality in human development to a concrete proposal for its measurement. I seek to introduce distributional concerns more directly into the discussions of, and policies promoting, human development. Absolute equality in income, longevity, and education, is certainly not possible (even if it were desirable): yet by suggesting why lesser inequality is preferable to greater inequality in each of these dimensions, I proceed to offer ways to measure such inequality.

\section{INFQUALITY IN DIMENSIONS OF HUMAN WELL-BEING AND DEVELOPMENT}

The idea of equality operates in a variety of disciplines-mathematics, the physical sciences, economics, philosophy, ethics, theology, inter alia-a fact which suggests both the disparate ways in which it can be employed, and its importance. The idea of human equality exists in a variety of moral and religious traditions; in contemporary times, it has been taken to be almost a necessary and selfevident concept for any moral system. ${ }^{3}$

Yel such conceptions of human equality stand in contrast to the empirical reality of inequalities of persons according to any standard of talent, intelligence, bcauty, as well as needs-basic or otherwise. It is this very diversity of human beings and their conditions that makes equality an interesting and important idcal. ${ }^{4}$

As Amartya Sen first argued in his Tanner Lecture of 1979, the consideration of equality as a moral concept always leads us to the question. "equality of what?"5 Posing this question does not remove the need to debate why we would want to discuss equality at all; rather, within a discourse in which most persons agree that equality is not objectionable, "equality of what?" more fully specifies the exercise. Sen effectively argues that most if not all constructive moral theories are based on, or depend upon, a notion of equality of something. For his part, John Rawis begins with cquality of primary goods; Ronald Dworkin has an understanding of "equality of resources," and so on. At base, utilitarians assume the equal value of an increase in each person's utility, and even libertarian theorists such as Robert Nozick, whose theory is criticized for having incgalitarian implications for wealth and income, defend an equal endowment of rights for all persons. All these "ethics of social arrangements" have some operative notion of equality.

Stated another way, equality is an important ethical ideal for each of these theories - what is at issue is the dimension, or space, of equality. As Sen (1992) has pointed out, if human beings were not so diverse, equality in one space might imply equality or near equality in other spaces. Yet given the fundamental nature of this diversity, striving for equality in one space almost necessarily implies a resultant inequality in other spaces. This is a crucial observation to bear in mind; it will figure into the construction of an Inequality-Adjusted HDI (section 7).

It is also important to note that in each space in which distributional questions of equality and inequality are discussed, questions of aggregation are also considered--e.g., "what is the total amount, or the average amount, of a particular good?" These aggregative questions do not take the distributional questions directly into account. ${ }^{7}$ There is often, then, a conflict between distributional and aggregative issues, ${ }^{x}$ this, too, must factor into the incorporation of inequality measures into the. HDI

As this paper considers equality and inequality as they relate to the HDI, we will focus on the spaces of income, education, and longevity. Why should we be concerned about equality in these three spaces? As will be discussed below, the case for equality in each of the three dimensions is distinct. Anand and Sen (1994) distinguish between an "efficiency argument" and an "equity argument" for defending equality in particular dimensions." The equity argument is most valid for dimensions that are considered intrinsically valuable-such dimensions contain human goods which all persons should possess at least in some minimum amount. In these spaces equality and inequality are matters of justice. On the other hand, the efficiency argument can be made for goodssuch as income--which are not necessarily valuable in themsclves but rather are means to intrinsic ends. Thus. a defense of reduced inequality of incomes is based on an efficiency argument asserting that lesser inequality of incomes leads to a more efficient societal use of income for obtaining other valuable social goods ${ }^{10}$ In contrast to income, longevity and education are each seen in the Human Development framework to be valuable as ends in themselves and as means to other important ends. Hence in these two dimensions, equality (or at least reduced inequality) can be defended for reasons of efficiency and equity.

\section{THE HUMAN DEVELOPMENT INDEX IN ITS PRESENT FORM}

This section critically reviews the Human Devel 
opment Index as it is currently conceptualized and measured.

A variety of interpretations of what the ends of development are-or should be-have factored into discussions of development economics since its inception." "Yet development economics has tended to focus on the growth of production as the principal objective, and as a result, questions of more intrinsic ends have been obscured. The improvement of living conditions has been valued most explicitly as a way to increase "human capital," an important input to the production process. Consequently, as Paul Streeten has noted:

A well-nourished. healthy, educated, skilled. alert labor force is the most important productive asset. This has been widely recognized, though it is odd that Hondas, beer, and television sets are often accepted without questioning as consumption goods. while nutrition. education, and health services have to be justified on grounds of productivity. ${ }^{12}$

Various alternatives to a growth-centered productivity approach to development have been offered. Besides the HDI, significant have been the "Physical Quality of Life Index" (PQLI), ${ }^{1.3}$ which evaluates three basic socioeconomic variables, and more recently, the work of Herman Daly and John Cobb, with the assistance of Clifford Cobb, on the Index of Sustainable Economic Welfare (ISEW). ${ }^{14}$ In addition, the "basic needs" approach has emphasized a particular bundle of necessary resources that every person ought to have in order to avoid absolute poverty. ${ }^{15}$

The "human development" approach, articulated in the United Nations Development Programme's (UNDP) annual Human Development Reports 199096, seeks to "put people back at the center of development." "As a way of indicating the degree of achicvement of the goals of this approach. the Human Development Index (HDI) was devised. Human development is about the expansion of people's choices; the IIDI itself is intended to indicate the level of attainment of some of those choices.

The Human Development Index thus attempts to encompass three important spheres of socioeconomic life, each of which captures a different dimension of economic chuices for well-being. These three spheres are income, education, and health. Income itself is seen instrumentally as a means to acquire basic goods and services, 17 indicating persons" access to resources needed for a decent standard of living. The real Gross Domestic Product (GDP) per capita is employed, but it is steeply discounted beyond the average world real GDP per capita. This discounting was designed to place emphasis on the basic income needed to acquire the goods and services required to meet a decent living standard, including things such as food, clothing, and shelter. ${ }^{18}$ In light of this adjustment to the income variable, this indicator of the HDI can be seen to reflect "basic-commodity opportunity."

The education variable is designed to indicate people's choices to acquire knowledge. In its most recent form, it includes adult literacy rates (weighted two-thirds) and the combined enrollment ratios for students at all levels of education (weighted onethird). Adult literacy is a "stock" concept, indicating what percentage of adults have acquired some minimal educational functioning (whether acquired from formal schooling or not from schooling). In contrast. school enrollment is technically a "flow" concept, reflecting what proportion of the (schoolage) population is currently in school. ${ }^{19}$ Together the two measures are intended to point to the more essential aspect of the dimension of education-to expand "knowledge opportunity." This knowledge opportunity can be seen as both a good in itself and as an instrument toward other meaningful ends. That is, knowledge attained in schooling is part of a welllived life and in itself is a crucial form of social participation; at the same time, it also expands choices of vocation and community involvement.

The health/longevity variable, life expectancy at birth, indicates the extent to which persons of a country are able "to live a long and healthy life."20 To be sure, indicators of longevity do not reveal directly the health-quality of those life spans. It is possible to live 80 years in poor health, ${ }^{21}$ or to live 20 or fewer years in perfect health before some unexpected death. Life expectancy is, of course, an aggregate measure for a population as a whole; on average, persons living in societies with higher life expectancies do tend to be in better health. To live a significant - and healthy-life span is seen as both a necessary means to other ends and as a good in itsclf. $^{22}$ This indicator points to the more essential element of this dimension-the expansion of "life opportunity."

To the extent that basic income, schooling, and life span are seen as means to other ends, there exists a question of what Amartya Sen has termed the "conversion rates" of these goods into other desired ends. ${ }^{23}$ That is, persons are not equally able to convert their "basic-commodity opportunities," "knowledge opportunities," and "life opportunities" into meaningful lives. Yet this conversion problem is not as severe as it is with measures such as GDP per capita, because these HDI variables Inore explicitly indicate essential elements of a well-lived life. In Sen's language, these variables more directly reflect a basic capability to function-and thus the HDI leaves a less severe "conversion rate" problem than do measures of per capita income-as we move from the means to the ends of human development. 
While the HDI measures achievements in basiccommodity, knowledge, and life opportunities, the very language of opportunity is meant to express a freedom to achieve other worthy ends in life, such as being well-nourished, being able to appear in public without shame, being a full participant in a society, etc. $^{24}$ Seen slightly differently, the achievements themselves reflect a freedom from early (premature) death, freedom from illiteracy, and freedom from material deprivation. These are what Sen (1992) has called "effective freedoms"- this type of understanding of freedom is indeed reflected in the HDI.

The HDI as it is presently constructed is determined for each country by combining these variables from each of the three dimensions as discussed above. The index $X_{i}$ for each dimension $i$ ( $i=1$ for income, $i=2$ for education, $i=3$ for longevity) for a given country is determined by the following formula:

$$
X_{i}=\frac{\text { actual } x_{i} \text { value }- \text { minimum } x_{i} \text { value }}{\text { maximum } x_{i} \text { value }- \text { minimum } x_{i} \text { value }}
$$

The assigned maximum value of $x_{i}$ is the greatest value that a country would be expected to have in that dimension. The minimum value of $x_{i}$ is the minimum that a country could achieve. In the case of education, the maximum obtainable value is 100 and the minimum is zero (reflecting a weighted average of literacy rates and educational enrollment, which are each expressed as percentages); in longevity the maximum life expectancy has been set at 85 and the minimum at 25 ; and in income the maximum adjusted real income per capita (for 1995) has been set at PPP $\$ 5,448$ (the adjusted value of a real GDP per capita of PPP $\$ 40,000)$ and the minimum is set at $\$ 100^{25}$

Hence the value of $X_{i}$ for each country in each dimension must fall between zero and one (inclusive). The value reflects the proportion achieved in the aggregate for each country, with values closer to one reflecting higher achievement levels. Conversely, the proportionate deficiency or shortfall of a country in a particular dimension is equivalent to (1$\left.X_{i}\right)^{26}$ We note here that the maximum potential for each country has been standardized-as has the minimum potential - and consequently achievement has been normalized on the $0-1$ scale. $^{27}$

The HDI itself is the average of $X_{1}, X_{2}$, and $X_{3}$ (the indices for income, education, and longevity). We can think of this as a weighted average where each index is weighted equally. ${ }^{28}$ That is,

$$
\mathrm{HDI}=\frac{\alpha X_{1}+\beta X_{2}+\gamma X_{3}}{\alpha+\beta+\gamma}, \text { where } \alpha, \beta, \gamma=1
$$

Since each $X_{i}$ must be a value between zero and one (inclusive), and HDI is a weighted average, HDI also must fall within the same range. The assignment of $\alpha, \beta$, and $\gamma$ is certainly arbitrary, though there is some empirical support, based on principal component analysis, for such an equal weighting. ${ }^{29}$ Certainly other weights could be assigned to the three indices if one's normative purposes called for it.

\section{DISTRIBUTIONAL PROBLEMS WITHIN THE HDI FRAMEWORK}

The HDI is a measure which reflects its aims imperfectly; and other important questions concerning human development are left out of the HDI altogether. The HDI has been criticized on a number of fronts. In fact, the authors have modified the index to address many of its sharpest criticisms, ${ }^{30}$ and thus the HDI has evolved over the seven issues of the Human Development Report. ${ }^{31}$ This paper is chiefly concerned with the fact that the HDI in its present form does not attend directly to distributional inequalities, a problem carefully considered in this section.

In the dimension of income, the discounting of a country's real GDP per capita measure lessens the impact on the HDI of any per capita rise above a certain threshold, which is the Gross World Product per capita $(\$ 5,120$ in the 1995 HDR). But this is only an adjustment on a country's per capita average figure-an aggregative measure. Thus, this discounting illuminates nothing about the distribution of income within countries themselves. In fact, it treats income above the threshold almost indifferently.

For the life expectancy calculation, no attention is paid to how that figure varies across particular persons, ethnic/racial groups, rural or urban status, gender, or class/caste. It is a probability-determined measure based on information drawn from aggregate life tables, and it is thus not a measure reflecting variation across individuals. For the most significant educational variable, adult literacy, only a country's overall rate is given - which conveys very crude information about how knowledge is distributed across the population. ${ }^{32}$

So the HDI, while it evaluates conditions in important dimensions of life, does not directly address distributional concerns.

The most concerted effort to look at issues of "inequality" in the Human Development Reports has been to disaggregate the specific indicators for various groups and to compare their outcomes. For instance, the HDR 1995 disaggregates the US data by racial/ethnic groupings, with important results: 
[W]ith the HDIs of white, black and hispanic populations separated, whites would rank number 1 in the world (ahead of Canada), blacks would rank number 27 (next to Luxembourg) and hispanics would rank number 32 (next to Unguay). So, full equality is still a distant prospect in the United States, despite affirmative action policies and market opportunities. ${ }^{33}$

The HDRs have also used disaggregation to explore the disparities between male and female achievements in the three indicators of the HDI, as well as in access to full participation and leadership in their societies. The Gender-related Development Index (GDI) is a calculation made by employing the same social indicators as the HDI but with data disaggregated by gender. The structure for calculating the GDI is particularly interesting because it allows for different weights to be assigned in the "tradeoff" between valuing improvements in particular disfavored groups (in this case, women) and valuing improvements for the overall population. ${ }^{34}$

It must be stressed that a measure such as the GDI, based on dala disaggregated for females and for males, is still aggregative in this sense: No information about the intrapopulation inequalities among females or among males is yielded. Hence this type of exercise is "group-based"; it explores the disparities of the respective aggregate measures between (or among) groups. Such an approach has the advantage of illuminating the average disparity of females and males-and thus emphasizing the need for development policies favoring, in this case, females as a group. This does, of course, achieve a good deal in indicating the inequalities of opportunities between males and females in a country. Yet by definition it does not address disparities that may be caused by other demographic factors. In addition, as previously stated, disparities within each gender are significant but not included. Thus, while this approach is based on disaggregation by groups, it is still at base an aggregative, and not distributional, index.

The HDR 1993 makes the most significant attempt to incorporate distributional, interindividual inequalities into its index. In what was termed an "Income-distribution-adjusted HDI," data about the distribution of income were used to adjust further the adjusted real GDP per capita figure $\left(x_{1}\right.$ in our terminology), which was then employed to compute the HDI. After the Gini coefficient, $G$, was calculated for each country (see section 5 for a fuller discussion of the Gini coefficient), the value of $x_{1}$ was multiplied by $(1-G)^{35}$ :

$$
\begin{aligned}
& X_{1}\left(\text { for the "Income }- \text { distribution }- \text { adjusted } \mathrm{HDI}^{\prime \prime}\right) \\
& =\frac{\text { actual } x_{1 *}(1-G)-\text { minimum } x_{1}}{\text { maximum } x_{1}-\text { minimum } x_{1}}
\end{aligned}
$$

This new $X_{1}$ was then used alongside the (unchanged) $X_{2}$ and $X_{3}$ to calculate the "Incomedistribution-adjusted HDI."

When this inequality-adjustment was made for income in the HDR 1993, it was argued that inequality was most extreme in the dimension of income, and therefore this dimension alone merited a calculation of intrapopulation distribution:

\begin{abstract}
The HDI is a national average, just like real income per capita, one of its components. The HDI therefore needs to be made sensitive to these distributions. It has the advantage that two of its three basic variables-life expectancy and educational attainment-are naturally distributed much less unequally than is income, the third variable. A rich person cannot live a thousand times longer than a poor person, though their incomes may be in that ratio. Across countries, the range of life expectancy is 42 to 79 , less than 2:1. Similarly, the percentage of adults who are literate ranges from $18 \% \mathrm{to}$ $99 \%$, a ratio of under $6: 1$. Mean years of schooling range from .1 to 12.3 , revealing greater differences than in life expectancy. ${ }^{36}$
\end{abstract}

There are a number of points raised here that need to be distinguished carefully. The above-quoted claim that life expectancy and educational attainment "are naturally distributed much less unequally than is income" can be made either across countries or across individuals within a given country. This claim is more true at the country level than at the individual level, as the HDR 1993 suggests. Particularly across individuals, there is indeed significant inequality in the spheres of education and longevity.

In order to illuminate these inequalities across persons, it is important to consider education and longevity in turn. In terms of education, literacy rates are a country or aggregate measure; an individual's "literacy" rate would be either one or zero. In order to demonstrate educational or knuwledge inequalities across individuals, a more informative indicator would be needed. For instance (as the HDR 1993 notes), years of schooling does varyfrom zero to 20 or more. In the sphere of longevity, life expectancy is a probability-based measure-an "expected value." Even when modified by all available demographic data to be used as a more "individual" indicator, ${ }^{37}$ the disparities remain less than the range of life spans actually lived. Life spans actually lived do indeed vary, from less than one year to over 100 years.

A central argument of this paper is that the dimensions of education and of longevity both have significant elements of intrapopulation inequalities-which could be measured if we moved beyond the actual indicators used in the HDI to consider the basal "good" in each dimension-" "knowledge opportunity" and "life opportunity." These are well 
reflected in individuals' lives in terms of "educational attainment" and "life-span attainment." There is significant inequality in each of these goods, and this inequality can be calculated alongside income inequality.

\section{CONCEPTUALIZING INEQUALITY IN INCOME, EDUCATION, AND HEALTH/ LONGEVITY}

This section presents the Gini coefficient as a workable, though imperfect, inequality measure for the purposes of this paper. A Gini coefficient will be employed in each of the spaces income, education, and health/longevity.

Inequality determinations can be distinguished between descriptive (or positive) and normative exercises. That is, we can distinguish between

positive measures which make no explicit use of any concept of social welfare, and normative measures which are based on an explicit formulation of social welfare and the loss incurred from unequal distribution. ${ }^{\text {is }}$

This distinction is not absolute; descriptive measures are appropriated for specific normative purposes and they even contain implicit concepts of social welfare. Conversely, normative measures do not precisely, or completely, capture the normative interests of the theorist. ${ }^{39}$

By this classification, the Gini coefficient is a descriptive measure. Widely used in considering distributions of income, it has a number of useful properties. The Gini coefficient is most easily seen geometrically, where the proportion of the ranked population is plotted against the population's cumulative holdings of a particular good. ${ }^{40}$ The Gini coefficient ranges from zero to one, with zero reflecting complete equality and one reflecting that one person holds all of the good, and all others hold none of it. Hence the greater the Gini, the greater the inequality. ${ }^{41}$ From one definition of the Gini coefficient it can be demonstrated that

the Gini coefficient implies a welfare function which is just a weighted sum of different people's income levels with the weights being determined by the rank-order position of the persons in the ranking by income level. ${ }^{42}$

Hence the Gini coefficient does include some implicit weighting, which gives greater emphasis to persons with lower holdings of the good in question. This leads Atkinson to remind us that

[m]easures such as the Gini coefficient are not purely 'statistical' and they embody implicit judgments about the weight to be attached to the inequality at different points on the income scalc. ${ }^{43}$
In fact, it is not possible to say that a lower Gini coefficient unambiguously implies lower inequality. As Atkinson (1970) proved, for any given good, one country A's inequality can be said to be unambiguously less than another country B's only if A's Lorenz curve lies inside B's curve at all points between $x=0$ and $x=1$-a situation of Lorenz. dominance. In other cases, such as when the Lorenz. curves cross at one or more points, the determination of inequality depends on normative assumptions about how to weight the various parts of the distribution.

Thus the Gini coefficient's operation is not purely descriptive, but rather it contains implicit normative assumptions about weighting different members (or classes) of the ranked population. These assumptions in themselves are not objectionable, but it does mean that when country A's Gini coefficient is greater than country B's, it can be said to have greater inequality only according to the weighting scale implicitly contained in the Gini's construction. ${ }^{+4}$

The Gini index also satisfies the "Pigou-Dalton criterion," which demands that any transfer from a poorer (or less educated, etc.) person to a richer (or more educated) person, ceteris paribus, increases the inequality measure. Yet the Gini coefficient fails to satisfy "the principle of regressive sensitivity to transfer," which would place more weight on transfers to persons at the bottom of the distribution. Rather, it attaches more weight to transfers in the middle of the distribution. ${ }^{+5}$ Further, the Gini coefficient is "mean independent": if every person in one country suddenly doubled her or his endowment of the good in question, the Gini coefficient would stay exactly the same. It is thus a relative measure only. ${ }^{46}$

While the Gini coefficient is most often employed to analyze distributions of income, it can be employed for looking at distributions of other goods as well. A Gini coefficient can be calculated for any good for which we know the amount that is held by each person (or household) within a given society. The task remains, then, to construct inequality indices in the spheres of education and longevity (and to refine the income inequality index).

In the space of income, each person holds some share of the total of the good income (for any given year). Analogously, in the space of education, we can think of there being a "stock" of educational attainment, which is reflected in the total number of years of schooling for that population. Each person holds some share of that total cducational attainment. Given the right data persons can be ranked according to their years of schooling, ranking them from least years of schooling to most years of schooling.

The relevant data for educational attainment (assuming that schooling is a good proxy for 
education) is thus the number of years of schooling attained in one's lifetime. The quality of schooling is not the same even within countries. This is a serious limitation, and if quality were accounted for, the distributional "inequality" of education would surely increase (since students with greater years of schooling probably received better-quality schooling along the way). But as there is no easy way to incorporate quality, educational attainment in years of schooling must be considered to be a conservative way to measure educational inequality. ${ }^{47}$

Analogously, though perhaps less intuitively, it is possible to talk about longevity achievement, or lifespan achievement. If longevity is seen as a good, then longer life spans are preferred to shorter life spans, and some inequality of life span exists across a society. One's age in years at death indicates, in fact, one's ultimate life-span attainment. The distribution in age at death thus reflects the inequality of life spans. (Of course, persons do not know precisely what their "ultimate stock" is, until their death.) Seen in this way, there is significant life-span inequality, ranging from infants who die at birth or before age one, to persons who die at ages over 100 years. Recent age-at-death statistics are the best measure available for determining life-span attainment, and its distribution. ${ }^{48}$

As is the case for income, the distributional measures for education and longevity say nothing about the mean attainment level. It is, of course, true that the increased achievement of a person at the high end of the distribution would increase the leve] of inequality. There is a dual effect of such a change: First, income inequality increases. But second, the achievement level — both for one individual and in the aggregate - has increased. Similarly, as a welleducated person gets more schooling without changing any one else's level of schooling, there results an increase in aggregate educational figures ${ }^{49}$ alongside a more unequal distribution of educational attainment. This reflects a tradeoff between increased aggregate attainment and decreased inequality. Valuing distribution versus aggregation is a normative exercise-which will be considered in detail in section 7. For now the point is that within each dimension of the IIDI, there is presently little or no question of such a tradeoff because distribution is not directly considered.

This section has shown that with the concepts of "educational attainment" and "life-span attainment" (and given sufficient data), a Gini coefficient can be calculated for each of the dimensions education and longevity. These measures may not be as "intuitive" as is the case for income, particularly because it is not customary to think of total stock of education (in total years of schooling) or of longevity (in the total number of years lived by persons who have recently dicd). But in cach of these important dimensions of human development, we have reason to be interested in distributional as well as aggregative measures. The distributional measures will be estimated in section 6 , and the consequent trade-offs between aggregation and distribution are taken up in section 7.

\section{ESTIMATING INEQUALITY IN INCOME, EDUCATION, AND LONGEVITY}

Data were obtained that made it possible to calculate Gini coefficients for income distribution, educational distribution, and longevity distribution. The required data for all three dimensions were available for an intersection of 20 developing countries. The Gini measures were calculated only for these countries, so that the same countries could be used in comparisons in all three dimensions. The data sets, and the calculations, for each of the three dimensions are now considered in turn.

The income distribution data were obtained from the World Development Report 1995 (World Bank, 1995). ${ }^{50}$ The data were already given in terms of income shares by quintile. Income share of the top $10 \%$ was also indicated. From this data, five points of the Lorenz curve, in addition to $(0,0)$ and $(1,1)$ could be derived straightforwardly. ${ }^{51}$ The Gini coefficient was determined from these seven data points. $^{52}$

The analogous Gini coefficient was calculated for educational attainment. Yet here the data set was not as neatly packaged for the calculation. The data were taken from the WDR 1995 Background Paper by Ahuja and Filmer (1995) which estimates educational attainment for developing countries. ${ }^{53}$ The data were classed by "no education," "some primary education," "completed primary education," "some secondary education," "completed secondary education," and "some higher education." 54

In the dimension of longevity, data were obtained from mortality statistics listed in the U.N. Demographic Yearbook 1992-Special Topic: Fertility and Mortality Statistics (United Nations, 1992). ${ }^{55}$ Age-at-death statistics were included for males and females for all available years from 1983-91. ${ }^{56}$ Since the data were already grouped by age-class, the midpoint number of years was assigned as the life-span attainment for each person in that age-class. This is a reasonable assumption. The areas of possible problem are for the age-class "less than one year," for which a life-span attainment of 0.5 was assigned, and "85 and above," for which a life span of 87 was assigned. ${ }^{57}$ With these age classes, it was a straightforward exercise to calculate the Gini coefficient for life-span attainment.

Results from these calculations are given in Table 1. All data and calculations for these threc 
Table 1. The HDI and distributive inequality measures for income, education, and longevity

\begin{tabular}{lcccccccc}
\hline Country & $\begin{array}{c}1995 \mathrm{HDI} \\
\text { world rk }\end{array}$ & $1995 \mathrm{HDI}$ & $\begin{array}{c}\text { Real GDP/ } \\
\text { Cap(\$PPP) }\end{array}$ & Inc-Gini & $\begin{array}{c}\text { Adult } \\
\text { literacy }\end{array}$ & Educ-Gini & $\begin{array}{c}\text { Life expectat } \\
\text { birth }\end{array}$ & $\begin{array}{l}\text { Life-Gini } \\
\text { Hong Kong }\end{array}$ \\
Costa Rica & 24 & 0.905 & 20340 & 0.39 & 91 & 0.36 & 78.6 & 0.15 \\
Korea (Rep.) & 31 & 0.883 & 5480 & 0.44 & 94 & 0.36 & 76.3 & 0.29 \\
Chile & 33 & 0.882 & 9250 & 0.33 & 97 & 0.33 & 71.1 & 0.21 \\
Venezuela & 47 & 0.850 & 8410 & 0.53 & 95 & 0.33 & 73.8 & 0.22 \\
Panama & 49 & 0.856 & 5520 & 0.42 & 90 & 0.43 & 71.7 & 0.35 \\
Mexico & 53 & 0.842 & 7300 & 0.49 & 89 & 0.37 & 72.8 & 0.32 \\
Colombia & 57 & 0.836 & 5480 & 0.49 & 90 & 0.38 & 69.3 & 0.38 \\
Thailand & 58 & 0.827 & 5950 & 0.42 & 94 & 0.35 & 69.0 & 0.27 \\
Malaysia & 59 & 0.822 & 7790 & 0.46 & 82 & 0.36 & 70.8 & 0.26 \\
Brazil & 63 & 0.804 & 5240 & 0.60 & 82 & 0.46 & 66.3 & 0.34 \\
Peru & 93 & 0.709 & 3300 & 0.44 & 87 & 0.40 & 66.0 & 0.51 \\
Dom. Rep. & 96 & 0.705 & 3280 & 0.48 & 81 & 0.48 & 69.6 & 0.45 \\
Sri Lanka & 97 & 0.704 & 2850 & 0.29 & 89 & 0.33 & 71.9 & 0.31 \\
Philippines & 100 & 0.677 & 2550 & 0.39 & 94 & 0.36 & 66.3 & 0.45 \\
Nicaragua & 109 & 0.611 & 2790 & 0.48 & 65 & 0.42 & 66.7 & 0.38 \\
Guatemala & 112 & 0.591 & 3330 & 0.57 & 54 & 0.55 & 64.8 & 0.58 \\
Honduras & 116 & 0.578 & 2000 & 0.57 & 71 & 0.46 & 67.7 & 0.39 \\
Zimbabwe & 121 & 0.539 & 1970 & 0.54 & 83 & 0.32 & 53.7 & 0.47 \\
Bangladesh & 146 & 0.364 & 1230 & 0.28 & 36 & 0.65 & 55.6 & 0.63 \\
\hline
\end{tabular}

Gini coefficients are contained in an Appendix available from the author. Alongside the 1995 HDI value and their component indicators, ${ }^{58}$ Gini coefficients are listed for each of the three dimensions. The Gini for income distribution is Inc-Gini; the Gini for educational attainment is Educ-Gini; and the Gini for life-span attainment is Life-Gini.

The correlation coefficients for these seven indicators are contained in Table 2 . As is well noted in the $H D R$, the correlations of the three respective components with the HDI itself are relatively high: .95 for adjusted real GDP/capita, .83 for adult literacy rate, and .85 for life expectancy at birth. These high correlations have been much discussed in the literature. ${ }^{59}$ The correlations between the inequality measures and the HDI are .09 for income inequality, -.65 for educational inequality, and -.83 for age-span inequality. For the latter two measures, the correlation runs as expected: lesser inequality in education and longevity corresponds to greater human development. Income inequality has no significant correlation with HDI, and further, the sign is not in the expected direction. Further, income inequality has almost no relationship to adjusted real GDP/capita-with a value of $.158^{.0}$

Within the other two dimensions, inequality correlates highly and negatively (as expected) with the relevant indicator. That is, Educ-Gini has a -.89 correlation to adult literacy (and a -.69 correlation to educational enrollment). Life-Gini has a -.78 correlation to life expectancy at birth.

How do the rankings compare in each of these seven variables: HDI, the three dimensional variables, and the three inequality variables? Table 3 lists each country's rank for each of these seven measures. ${ }^{61}$ For the Gini coefficients, the higher rank (e.g., a "l") denotes less inequality.

Consistent with the correlation findings, the various indicators show some tendency to move together, but there are significant observations to be

Table 2. Correlations of HDI, HDI components, and distributional inequality indices

\begin{tabular}{|c|c|c|c|c|c|c|c|}
\hline & HDI & $\begin{array}{l}\text { Adj. real GDP/ } \\
\text { cap }\end{array}$ & Inc-Gini & Adult lit. & Educ-Gini & $\begin{array}{l}\text { Life expect. at } \\
\text { birth }\end{array}$ & Life-Gini \\
\hline HDI & 1 & & & & & & \\
\hline Adj.GDP/cap & 0.9473 & 1 & & & & & \\
\hline Inc-Gini & 0.0881 & 0.1576 & 1 & & & & \\
\hline Adult Lit. & 0.8269 & 0.6450 & 0.0040 & 1 & & & \\
\hline Educ-Gini & -0.6500 & -0.4668 & 0.0019 & -0.8877 & 1 & & \\
\hline Life Expect. & 0.8457 & 0.7388 & -0.0463 & 0.6186 & -0.4720 & 1 & \\
\hline Life-Gini & -0.8317 & -0.7502 & 0.0525 & -0.7160 & 0.7179 & -0.7844 & 1 \\
\hline
\end{tabular}


Table 3. Country rankings by HDI, component indicators, and inequality indices

\begin{tabular}{|c|c|c|c|c|c|c|c|}
\hline Country & HDI & GDP/cap. & Inc-ineq & Adult lit. & Educ-ineq & Life expect. & Age-ineq \\
\hline Hong Kong & 1 & 1 & 5 & 6 & 8 & 1 & 1 \\
\hline Costa Rica & 2 & 9 & 9 & 3 & 7 & 2 & 6 \\
\hline Korea (Rep.) & 3 & 2 & 3 & 1 & 2 & 7 & 2 \\
\hline Chile & 4 & 4 & 15 & 2 & 3 & 3 & 3 \\
\hline Ventezuela & 5 & 3 & 7 & 7 & 15 & 6 & 11 \\
\hline Panama & 6 & 8 & 17 & 9 & 10 & 4 & 8 \\
\hline Mexico & 7 & 6 & 13 & 11 & 12 & 8 & 12 \\
\hline Colombia & 8 & 10 & 14 & 8 & 11 & 11 & 10 \\
\hline Thailand & 9 & 7 & 6 & 5 & 5 & 12 & 5 \\
\hline Malaysia & 10 & 5 & 10 & 15 & 9 & 9 & 4 \\
\hline Brazil & 11 & 11 & 20 & 14 & 17 & 15 & 9 \\
\hline Peru & 12 & 13 & 8 & 12 & 13 & 17 & 18 \\
\hline Dom. Rep. & 13 & 14 & 12 & 16 & 18 & 10 & 15 \\
\hline Sri Lanka & 14 & 15 & 2 & 10 & 4 & 5 & 7 \\
\hline Philippines & 15 & 17 & 4 & 4 & 6 & 16 & 16 \\
\hline Nicaragua & 16 & 16 & 11 & 18 & 14 & 14 & 13 \\
\hline Guatemala & 17 & 12 & 19 & 19 & 19 & 18 & 19 \\
\hline Honduras & 18 & 18 & 18 & 17 & 16 & 13 & 14 \\
\hline Zimbabwe & 19 & 19 & 16 & 13 & 1 & 20 & 17 \\
\hline Bangladesh & 20 & 20 & 1 & 20 & 20 & 19 & 20 \\
\hline
\end{tabular}

made from the additional information. The $H D R$ $1995^{62}$ reported that Sri Lanka and Zimbabwe had both made significant efforts to lessen female illiteracy-these efforts are supported by the relatively high rankings that each country receives on Educ-Gini (fourth and first, respectively). These are higher ranks than their overall HDI (14th and 19th) as well as their ranks in adult literacy (10th and 13th).

In terms of income inequality, Brazil is shown to have the most disturbing, disparate income distribution, ranking 20th of the 20 countries. This is consistent with the findings of the $H D R 1993 .^{63} \mathrm{In}$ contrast, Sri Lanka's income inequality ranks second among the countries (while its real GDP/capita ranks only 15 th). It would be interesting to note the relationship(s) between a relatively even income distribution and Sri Lanka's relatively even educational attainment - as well as its respectable literacy rate. Interestingly, the figures for Bangladesh indicate that while it had the lowest real GDP/capita, it had the most equal income distribution. This is a case of income deprivation being well distributed; it is thus also a reminder that distributional statistics must be seen alongside aggregative ones (and vice versa).

Life expectancy at birth and Life-Gini tend to yield similar ranks, though countries like Korea, Thailand, and even Brazil seem to do significantly better on life-span distribution than they do on life expectancy. Conversely, Costa Rica, Venezuela, and the Dominican Republic fare better on life expectancy than on life-span inequality. More work needs to be done in this area in order to understand these results.
Finally, we can say something about the correlations between the Gini coefficients in the three dimensions. The correlation between the Gini coefficient for income and that for life span is .053. The correlation between Inc-Gini and EducGini was .002 . The only significant correlation was between the respective Gini coefficients for education and life span-this came in at .718. These results are consistent with the fact that income inequality was not strongly related to any human development indicator. These results taken together are a reminder that levels of inequality in some spaces are not necessarily related to inequalitics in other spaces. Inequality in education and longevity, however, like their respective aggregate measures, are positively and relatively strongly related. ${ }^{64}$

Inequality, then, as it is indicated by the Gini coefficient, can be estimated in all three dimensions of the Human Development Index. While there are data limitations, and some intertemporal and comparability problems, the Gini coefficients offer information about inequalities of distribution that is not captured in the aggregative figures.

\section{THE INEQUALITY-ADJUSTED HDI (IAHDI)}

Is there reason to combine the information already reflected in the HDI with the three inequality measures into one scalar indicator that reflects both aggregation and distribution?

The answer depends on the normative ends of the exercise. It has been argued that the information contained in the three dimensions of the HDI is more 
meaningful than the HDI itself. Yet, the three components were indeed combined in an equally weighted average to determine a single HDI. This was done in order to yield one simple indicator of "human development" which offered an alternative to income- and growth-centered indicators such as GNP/capita.

If this is an important goal of the $H D R$--to have one index which reflects human development-then it can be argued that distributional measures should be a part of such an index. The HDI aggregative indices for basic-commodity opportunity, knowledge opportunity, and life opportunity give an adequate snapshot of human development, but inequalities in each of these spheres can be incorporated for a fuller picture.

It could be argued, then, that one should prefer the Gender-related Development Index (GDI) to the HDI, because it addresses inequalities between male and female aggregate attainment. But this essay offers a complementary measure, since an exclusive emphasis on gender-based inequalities leaves other types of inequalities tnaddressed (see section 4, above). Below is proposed a way to combine the aggregative and distributional data we have already calculated to arrive at an Inequality-Adjusted HDI (IAHDI).

The proposed index is constructed as a modification of the HDI. How are the three indices comprising the HDI to be modified? Recall that each index of the HDI is calculated by the formula

$X_{i}=\frac{\text { actual } x_{i} \text { value }- \text { minimum } x_{i} \text { value }}{\text { maximum } x_{i} \text { value }- \text { minimum } x_{i} \text { value }}$

The denominator reflects the total span of possible achievement in a given dimension-the distance between the minimum potential value and the maximum; the numerator measures the proportion of that span which has been achieved. In computing the IAHDI, the proportion achieved (the numerator) should be adjusted downward, or discounted, by a figure reflecting the inequalities for that dimension. One straightforward way to accomplish this is to multiply the numerator by $\left(1-G_{i}\right)$, where $G_{i}$ is the Gini coefficient for each dimension $i(i=1,2,3)$, a technique for which there is significant precedent. ${ }^{65}$

If this calculation were made in each dimension, however, we would be reducing the index $X_{i}$ from each dimension, on average, by a different factor, since the mean of each dimension's $G_{i}$ (Inc Gini, Educ-Gini, and Life-Gini) is not the same. Further, and just as important, it is not immediately obvious whether we would want to adjust each dimension's indicator by an equal proportion (on average). For various normative reasons we might want to emphasize inequality, say, in the two more intrinsi- cally valuable dimensions. Or conversely, if we felt that the most important (or unique) information about distribution was contained in the Gini for income, then we might weight it more. In order to enable such a choice of weighting, we are flexible in defining our dimensional indices, called Inequalityadjusted $X_{i}$, or $I A X_{i}$, for $i=1,2,3$ :

$$
\begin{aligned}
& I A X_{i} \\
& \qquad=\frac{\left(\text { actual } x_{i} \text { value }- \text { min. } x_{i} \text { value }\right) * \lambda_{i}\left(1-G_{i}\right)}{\operatorname{maximum} x_{i} \text { value }-\operatorname{minimum} x_{i} \text { value }}
\end{aligned}
$$

which is equivalent to

$I A X_{i}=X_{i} * \lambda_{i}\left(1-G_{i}\right)$

For each dimension $i, \lambda_{i}$ is the weight given to inequality-adjustment factor. Presumably, $\forall i,(1 /(1-$ $\left.\left.G_{i}\right)\right)>\lambda_{\mathrm{i}}>0$.

Thus, each dimensional index of the HDI is adjusted for inequality by a factor of $\lambda_{i} *\left(1-G_{i}\right)$. This weighting, of course, does not change the fact that the dimensional indices comprising the HDI can be weighted differently than their present $\alpha, \beta, \gamma=1$. Thus the IAHDI is calculated in an analogous fashion to the HDI:

$$
\mathrm{IAHDI}=\frac{I A X_{1}+I A X_{2}+I A X_{3}}{\alpha+\beta+\gamma}
$$

While the weights could be adjusted, I have calculated an IAHDI according to a simple weighting system of $\alpha, \beta, \gamma_{1}, \lambda_{1}, \lambda_{3}=1$. The results are contained in Table 4. In Table 5, the rankings of countries by HDI and IAHDI are given. The change in ranks from the HDI to the IAHDI are also indicated.

In determining the IAHDI for each country by the process of discounting the components as described herein, the percentage loss in HDI ranged from a low of 29.6 for the Republic of Korea to 56.6 for Guatemala and Bangladesh. As a consequence, Guatemala fell by two spots, Bangladesh had no further to fall, and the Republic of Korea passed one of the two countries ahead of it in the HDI rankings. With respectable adjustments for inequality, Sri Lanka, Malaysia, and Thailand moved up in the rankings by three, four, and four spots, respectively.

The calculation of the IAHDI is a way to incorporate distributional patterns from all three dimensions of the HDI into a composite index. Seen in this way, the IAHDI is thus a refined, scalar index which combines a great deal of information in a way that is still meaningful for human development. The 
Table 4. The HDI and the Inequality-Adjusted Human Development Index (IAHDI)

\begin{tabular}{llll}
\hline Country & I995 HDI & IAHDI & $\begin{array}{c}\text { Percentage } \\
\text { loss }\end{array}$ \\
\hline Hong Kong & 0.905 & 0.633 & 30.1 \\
Costa Rica & 0.883 & 0.561 & 36.5 \\
Korea (Rep) & 0.882 & 0.621 & 29.6 \\
Chile & 0.880 & 0.553 & 37.2 \\
Venezuela & 0.859 & 0.513 & 40.3 \\
Panama & 0.856 & 0.499 & 41.7 \\
Mexico & 0.842 & 0.488 & 42.1 \\
Colombia & 0.836 & 0.492 & 41.1 \\
Thailand & 0.827 & 0.539 & 34.9 \\
Malaysia & 0.822 & 0.519 & 36.9 \\
Brazil & 0.804 & 0.416 & 48.3 \\
Peru & 0.709 & 0.393 & 44.6 \\
Dom. Rep. & 0.705 & 0.375 & 46.8 \\
Sri Lanka & 0.704 & 0.483 & 31.4 \\
Philippines & 0.677 & 0.410 & 39.5 \\
Nicaragua & 0.611 & 0.354 & 42.1 \\
Guatemala & 0.591 & 0.256 & 56.6 \\
Honduras & 0.578 & 0.317 & 45.1 \\
Zimbabwe & 0.539 & 0.316 & 41.4 \\
Bangladesh & 0.364 & 0.158 & 56.6 \\
\hline
\end{tabular}

IAHDI, in fact, combines six measures an aggregate and a distributional indicator for each of three dimensions. ${ }^{66}$ Of course, these six measures seen separately communicate more information than the single IAHDI. Yet the system of weights would allow persons to combine these six indicators with the normative flexibility to place emphasis on particular aspects of human development.

Table 5. Country rankings by HDI and IAHDI

\begin{tabular}{lrrr}
\hline Country & HDI & IAHDI & $\begin{array}{c}\text { Change in } \\
\text { ranks }\end{array}$ \\
\hline Hong Kong & 1 & 1 & 0 \\
Costa Rica & 2 & 3 & -1 \\
Korea (Rep.) & 3 & 2 & 1 \\
Chile & 4 & 1 & 0 \\
Venezuela & 5 & 7 & -2 \\
Panama & 6 & 8 & -2 \\
Mexico & 7 & 10 & -3 \\
Colombia & 8 & 9 & -1 \\
Thailand & 9 & 5 & 4 \\
Malaysia & 10 & 6 & 4 \\
Brazil & 11 & 12 & -1 \\
Peru & 12 & 14 & -2 \\
Dom. Rep. & 13 & 15 & -2 \\
Sri Lanka & 14 & 11 & 3 \\
Philippines & 15 & 13 & 2 \\
Nicaragua & 16 & 16 & 0 \\
Guatemala & 17 & 19 & -2 \\
Honduras & 18 & 17 & 1 \\
Zimbabwe & 19 & 18 & 1 \\
Bangladesh & 20 & 20 & 0 \\
\hline
\end{tabular}

\section{CONCLUSIONS}

If the HDI helps "to put people back at the center of development," then the IAHDI takes more seriously the distributional question, Which people? This paper has moved from the concept of inequality and the conceptualization of the Human Development Index to devise ways of incorporating considerations of inequality into the HDI. It has been argued that distributional inequalities in income, education, and longevity are significant concerns for human development and well-being; and that they are not adequately addressed in the HDI in its present form. To conceptualize and calculate these inequalities, it has been necessary to move behind the particular indicators of the HDI itself to look at the more basal goods in the three dimensions. These inequality measures have been consistent with the main objective of the HDI: to measure the level of human choices in important dimensions of life-or, in other words, to assess basic-commodity opportunity, knowledge opportunity, and life opportunity.

Surely the construction of inequality measures in these three dimensions based on Gini coefficients face conceptual as well as empirical difficulties. Inequality of longevity is a difficult concept intuitively. The Gini coefficient is not a perfect indicator of inequality-it is neither fully "objective" nor does it respond completely adequately to transfers. "Rankings" of countries for inequalities by their Gini measures depends on the implicit welfare function of the Gini calculation. The data for distribution in all three dimensions have comparability and reliability problems. None of these or other problems should be downplayed.

On a more positive note, this attempt to incorporate distributional inequality does make it possible to account for more information than is currently part of the HDI. With improvements in international data, the accuracy of these inequality indices will be improved; and data for more countries will be available. Actually, the data requirements for these calculations arc not cxcessively demanding, and they draw largely from census data in specific countries, the most reliable form of socioeconomic data. In addition, the InequalityAdjusted HDI offers significant flexibility in weighting inequalities within a Human Development framework.

What are the implications of adjusting the HDI to account for inequalities? One important finding is that most Latin Amcrican countrics, a region known to have the most severe income distribution problem, fall in rank when inequality is factored into development. That is, if we conceptualize development without inequality by using the HDI in its present form, the Latin American countries do relatively well; that evaluation shifts significantly 
when inequality is counted in via the IAHDI. Another implication is that inequality is shown to be a problem not just in income, where it is arguably most severe, but in education and health, where inequalities are perhaps seen as more troubling. The IAHDI framework allows for addressing all of these inequalities, and they can be weighted according to the aims of the exercise.

Further, measures of inequality of income have been criticized because income-based poverty is sometimes only temporary; income-inequality measures such as the Gini coefficient do not directly address the permanence of the distribution. Educational and health/longevity inequality are more permanent phenomena and thus are more clearly of social import, and even moral concern. ${ }^{67}$

Finally, to incorporate distributional concerns via the IAHDI is to promote a "rhetoric of inequality" within discussions of human development. Just as the Human Development Index has managed to shift discussions beyond talk of the Gross National or Domestic Product, the Inequality-Adjusted HDI should inject distributional concerns more explicitly into policy-making discourse in the contexts in which the Human Development Reports are widely used: UN agencies, nongovernmental organizations (NGOs), and government agencies.
1. This involved discounting the real income-per-capita figure to account for income inequality (see HDR 1993, "Technical note 1," pp. 101-102) and section 4, below.

2. An important attempt to look at the disparities between males and females in literacy rates, life expectancy, and real income has been made in the design of a "Gender-related Development Index (GDI)" - sec especially HDR 1995, "Technical notes 1 and 2," pp. 125-133. The GDI is based on disaggregating data by gender-and calculating "inequality" by comparing the discrepancies between women's attainment and overall attainment. More is said about these measures below-especially in sections 4 and 5.

3. For example, as presented in Hare (1952, 1963); see also Williams (1962) and Sen (1992).

4. Preston (1986); see also Sen (1992).

5. $\operatorname{Sen}(1980,1992,1993)$.

6. Sen (1992, chapter 1), Rawls (1971), Dworkin (1981), Nozick (1974). Notice that Rawls defends an equal basket of basic liberties for all (and not an equality of liberty in general). The same can be said for Nozick: His libertarian vision entails a (more) limited notion of particular rights. Of course, Rawls's "second principle" moves beyond liberties to consider the just distribution of other "primary goods."

7. If, however, a particular commodity can only be "possessed" or "not possessed" — such as literacy-then the aggregate total does reflect straightforwardly the distribution in a society. For example, the aggregate percentage of persons who are literate in a society is the literacy rate, which indicates the "haves" and the "have nots" directly. But as I argue below (section 5), much more can be said about the space of education than is reflected in a "yes or no" measure such as literacy rates.

8. See Sen (1992, pp. 136-138).

9. Anand and Sen (1994: p. 3).
10. A standard argument for equality of incomes asserts that if all persons have diminishing marginal returns to income in terms of utility, and if persons are assumed to have identical and interpersonally comparable utility functions, then utility is maximized when incomes are equal. An efficiency argument for income vis-à-vis other valuable social goods does not depend on utilities at allthough similar assumptions would have to be made that the "conversion rates" from income to valuable social goods have diminishing marginal returns for each person, and that they are interpersonally comparable and identical. An even more egalitarian position could assert that many persons who are disabled or otherwise impaired-persons who in general would be located at the lower end of socioeconomic distributions-are inefficient in converting income into other valuable goods, and hence they would need to hold more income in order to achieve the same level of other goods. See Sen (1992).

11. For a discussion of the dominant themes in development economics and an argument for more emphasis on the expansion of people's capabilities, see Sen (1983). For one critique of development as it has been linked to "modernization" as well as of development as expansion of capabilities, see Marglin (1990).

12. Streeten (1994, p. 232).

13. The PQLI is explained in Morris (1979).

14. The ISEW is first presented in Daly and Cobb (1989).

15. See Streeten et al. (1981) for a variety of perspectives on the "basic needs approach."

\section{6. $H D R 1995$, p. 11 .}

17. For an informative empirical study of the impact of income as a means to "the goal of the capability to live a long, healthy, and active life," see Anand and Ravallion (1993).

18. Gross Domestic Product is used instead of Gross National Product in order to avoid problems of exchange 
rates. The GDP is expressed in Purchasing Power Parity (PPP) dollars in order to obtain rough comparability of access to basic goods and services across societies. For the discounting formula in the adjustment of GDP/capita, see HDR 1995 "'Techrical note 3"' (pp. 134-135).

19. The HDR 1995 notes that the indicator of combined enrollment ratios "shows the stock of literacy quite easily for those under age 24" ("Technical note 3," p. 134). This is only because the literacy rate is such a basic educational indicator.

\section{HDR 1995, p. 11.}

21. Most persons who manage to live to 80 in poor health have benefited from significant medical attention, which is often, though not always, associated with high incomes. I am grateful to Paul Streeten for pointing out that "at low income levels, morbidity and mortality are closely related."

22. It is of course possible to argue that merely living and breathing on this earth for some duration is not a good-initself at all; rather, only a well-lived life is of any value. While this is certainly an important moral question, it is beyond the scope of this essay. Even if such an objection is sustained, we would still view the expansion of life opportunity as an important, albeit instrumental, good.

23. See in particular Sen $(1992,1993)$ for issues surrounding persons' differing "conversion rates" of goods into other goods.

24. I am here borrowing from Professor Sen's distinction between freedom and achievement, as well as from his conceptualizations of capabilities and functionings. For a succinct discussion, see Sen (1993).

25. The most recent discussion of "computing the human development index" is contained in "Technical note 3" of the Human Development Report 1995 (pp. 134-135). See also Anand and Sen (1994).

26. In earlier editions of the $H D R$, the HDI was calculated with deprivation as a more fundamental concept than achievement. Some persons (such as Srinivasan, 1994) still discuss the HDI as measuring deprivation, which is no longer precisely accurate.

27. To be sure, problems of comparability still remain to the extent that "literacy" does not mean the same thing in one country as compared to another; or to the extent that the expression of income in PPP dollars does not reflect equivalent access to similar baskets of basic commodities. To such difficulties as these must be added the plethora of data-reliability problems, noted below.

28. The question of weighting will be revisited in section 7.

29. See $H D R 1993$ “'Technical note 2," pp. 109-110.

30. For instance, T.N. Srinivasan continues to be a sharp critic of the HDI-see Srinivasan (1994). For defenses of the HDI as it has evolved, see for instance Anand and Sen
(1994). For an instructive empirical discussion relating to public policy consistent with the goals of the HDI, see Anand and Ravallion (1993).

31. For instance, the HDI as it was originally formulated did not assign fixed values for the maximum and minimum values of the three dimensions' respective indices; rather, maximum and minimum values were taken from the actual reported country values $x_{i}$. Consequently, as a relative index in any given year there was no problem with this method, but intertemporally this was problematic; it was a case of "moving goal posts" for particular countries. That is, each country's value for any given year in any dimension depended upon the performance of the best and worst performing countries as well as on its own. Critics pointed out this weakness; it was rectified with the assignment of "fixed goal posts." The HDR 1993 "Technical note 2"' takes up this criticism, as well as others, and considers alternatives for the HDI.

32. Fach person is treated as either a " 0 " if illiterate or as a " 1 " if literate.

\section{HDR 1995, p. 22.}

34. The most significant treatment of the GDI and other gender-related questions of human development is contained in "Technical note l" of the HDR 1995. This technical note is based on Anand and Sen (1995).

35. In other words, $x_{i}$ was replaced by $(1-G)^{*} x_{i}$. My calculation for an inequality-adjusted index $X_{1}$ is calculated in a slightly different way (see section 7 ).

36. HDR 1993, p. 101. Streeten (1994) echoes the need to emphasize inequality in income more than in life expectancy or in literacy. He writes that "high incomes of some can cause relative deprivation in others. This is not true for human indicators. If anything the benefits in the health and education of anybody benefit the whole community" (pp. 235-236). This is not necessarily the case. There are positive externalities associated with good health and educational background, to be sure. But these goods can be used selfishly just as income is; education or health, like income, can be used to exploit others. Thus it is not clear that the education and health of some always benefit the community as a whole, or more specifically. those at the bottom of socioeconomic distributions.

37. In order for an individual's life expectancy at birth to vary from other individuals in the same country, more demographic information would have to be given-e.g., that a baby was female, Hispanic, smoker-parents, etc. See also Anand and Sen $(1994$, p. 5).

38. Sen (1973, p. 24). This distinction is applied to a host of inequality measures in Sen's On Economic Inequality (1973, chapter 2). For another careful analysis of inequality measures and social welfare, see Osmani (1982; chapter 3).

39. Sen (1973, p. 3).

40. The relationship of the Lorenz curve and the Gini coefficient are carefully explored in Anand (1983; Appen- 
dices B "The Gini coefficient" and D "Lorenz Dominance and Inequality") and in Osmani (1982; Appendix 2, "The algebra of the Lorenz curve"). A simpler exploration is given in Atkinson (1983; chapter 1).

41. Anand (1983) offers six equivalent definitions of the Gini coefficient. We will employ his definition \#1 to estimate Gini coefficients for distributions of income, longevity, and education, below.

42. Sen (1973; pp. 30-32). This formula is: $G=1+(1 / n)-\left(2 / n^{2} \mu\right)\left[y_{1}+2 y_{2}+\ldots+n y_{n}\right]$ for $y_{1} \geq$ $y_{2} \geq \ldots \geq y_{n}$, and where $\mu=$ the mean of $\left(y_{1}, y_{2}, \ldots, y_{n}\right)$. For a further discussion, see Sen (1973; chapter 2) and Osmani (1982; pp. 314-316).

43. Atkinson (1983; p. 56). For an "intuitive" discussion based on the geometry of the Lorenz curve, see Sen (1976, especially section 6).

44. This is why Sen (1981) ranks developing countries only partially, according to Lorenz dominance. He concludes that in many cases, the Lorenz curves for income distribution of differing countries cross, leaving only a partial ordering of countries by this measure. He argues that this is the only "noncontroversial" way to rank countries for inequality. This implies that the use of the Gini coefficient in this essay does not lead to an "objective" ranking of countries' inequalities.

45. These properties of the Gini coefficient were first established by Atkinson (1970). See also Osmani (1982; pp. $38-41)$ and $\operatorname{Sen}(1973,1976)$.

46. $\operatorname{Sen}(1973$, pp. 36,69$)$.

47. Ahuja and Filmer (1995) note the same problem, and draw the same conclusion.

48. There is a significant intertemporal problem with treating longevity outcomes, for only when persons die do we obtain their ultimate life-span achievement, and it is the ultimate figure in which we are interested. A person who dies in 1985 at age 85 has survived conditions that were very different than, say, those of a five year-old who also dies in 1985. The death statistics for the year 1985, then, are the outcome measures for persons whose life spans varied in duration. These problems are arguably no more severe than problems of estimating life expectancies (looking into the future) based on present-day life tables.

49. The literacy rate, presumably, would not change. But educational enrollment, and more significantly for the study, total years of schooling, would both increase.

50. These figures are found in Table 30-Income Distribution and PPP estimates of GNP, pp. 220-221.

51. To be sure, there are reliability and comparability problems with the WDR data set. First, for some countries, the data are for consumption and for other countries the data are for income. Income tends to be more unequal than consumption, since the wealthy can more readily use their income for nonconsumptive purposes--e.g., savings. But there is precedent for using income and consumption data in comparative exercises. For example, Anand and Kavallıon (1993, p. 141) use both household consumption and income data for looking at the distribution of consumption. Further, some countries' distributional data are based on houscholds, and others' are based on individuals; household data obscure intrahousehold distributions. The data, mostly received from household surveys, are the most recent available for each country, varying from 1979 to 1993. With all these caveats, this is the best income distribution set available. See WDR 1995 technical notes to tables, pp. 242-244, for further discussion of this data set.

52. The Gini coefficient was determined by the following definition: For $i=0$ to $n$. let $F_{i}$ be the cumulative proportion of the population, and let $\Phi_{i}$ be the cumulative proportion of the total quantity of the relevant good. (Thus, the points along the Lorenz, curve are $\left(F_{2}, \Phi_{1}\right)$.) Then $G=1-\sum_{i=0}^{n-1}\left(F_{i+1}-F_{i}\right) *\left(\Phi_{i-1}+\Phi_{i}\right)$ This result can be seen geometrically in Anand (1983, p. 312). The same formula is used to calculate Gini coefficients in educational and life-span attainment.

53. The Ahuja and Filmer data set appeared to be the best available for the purposes of this essay. The data set begins with the Barro and Lee (1993) estimates of educational attainment, whose data were obtained principaly from country-specific census data. Ahuja and Filmer then employed a "flow" analysis based on dropout and enrollment rates to arrive at estimates into the future and to expand Barro and Lee's data set to all those from age six to 60 who had completed their education. The data set employed in my calculations was Ahuja and Filmer's estimates for 1985 .

54. Following the authors precedent, the quantity of schooling-years assigned to each of these classes is, respectively, $0,3,6,9,12$, and 15 . There are some comparability problems with this assumption. According to the "ISCED" standards for measuring educational enrollments across countries. the quantity of primary and secondary schooling is not constant. The actual ISCED standards are given in Table 3 of the UNESCO '95 Statistical Yearbook (UNESCO, 1995). Because Ahuja and Filmer utilized the assignment of values discussed above in arriving at their estimates-assuming a six-year span for primary, and a six-year span for secondary education-I needed to maintain their assumption. Further, even without comparability problems, the educational attainment numbers assigned for each class are imprecise. These caveats all must be noted before making the Gini calculation, which is straightforward once these classes of educational-attainment have been created.

55. These statistics are given in Table 22-Deaths by age, sex, and rural/urban residence 1983-1991.

56. The number of years for which these data were available varied from one to nine years. All available data were used in the case of each country, in order to lessen, where the data were available, the effects of distributional variation across years. In actuality, this variation was slight, and thus countries were not excluded even if data for only one year were available. Other possible problems with this 
data set are given in the technical notes to Table 22, U.N. Demographic Yearbook 1992-Special Topic: Fertility and Mortality Statistics, pp. 86-89.

57. In all likelihood, the actual mean age-attainment of the former class was less than a half-year, due to a high incidence of deaths at or near birth. The actual mean ageattainment of the latter class could have been somewhat higher, but there is no way to know the precise mean. These assumptions were the best that could be conceived.

58. For the educational component, for the sake of parsimony, only adult literacy rates are included. (These count two-thirds, while educational enrollment counts onethird, in the determination of the education indicator of the HDI.)

59. See the literature review in $H D R 1993$.

60. In fact, the correlation between income inequality and non-adjusted GDP/capita is -.12 . This has the opposite sign, which further bears out that there is no significant relationship between Inc-Gini and real income per capita.

61. The caveat is repeated that the Gini coefficient as an inequality index depends on the implicit welfare assump- tions of the index. The rankings by Gini coefficient are not based on purely "descriptive" assumptions-see section 5 .

62. HDR 1995 , p. 32.

63. HDR 1993, pp. 17, 55.

64. The correlation hetween adult literacy rate and life expectancy at birth was .62. The relationship between the distributional measures thus appears, in fact, to be stronger.

65. See Sen (1976) on the technique and social welfare implications of discounting mean regional incomes by (1G); see Klasen (1994) for an examination of "distributionweighted" growth rates in the post-War United States; and see the $H D R 1993$ for an "income-distribution-adjusted HDI." For that calculation, however, only the actual $x_{1}$ value, and not the entire numerator, was multiplied by ( 1 G).

66. The aggregate measure for education is itself a composite of adult literacy rate and combined enroliment ratios. See section 3 .

67. I am indebted to Paul Streeten for noting this important implication of the IAHDI.

\section{REFERENCES}

Ahuja, V. and Filmer, D. (1995) Educational attainment in developing countries: New estimates and projections disaggregated by gender. Background Paper for the World Development Report 1995, The World Bank, Washington DC.

Anand, S. (1983) Inequality and Poverty in Malaysia: Measurement and Decomposition. Oxford UP for the World Bank, Oxford.

Anand, S. and Ravallion, M. (1993) Human development in poor countries: On the role of private incomes and public services. Journal of Economic Perspectives 7(1), $133-150$.

Anand, S. and Sen, A. (1994) The human development index: Methodology and measurement. Human Development Report Occasional Paper no. 12, UNDP, New York.

Anand, S. and Sen, A. (1995) Gender inequality in human development: theories and measurement. Human Development Report Background Paper, UNDP, New York.

Atkinson, A.B. (1970) On the measurement of inequalilty. Journal of Economic Theory 2, 244-263.

Atkinson, A.B. (1983) The Economics of Inequality. Second Edition. Clarendon Press, Oxford.

Barro, R. and Lee, J.-W. (1993) International comparison of educational attainment. Journal of Monetary Economics 32, 363-394.

Daly, H. and Cobb, Jr., J. B. (1989) For the Common Good: Redirecting the Economy Toward Community, the Environment, and a Sustainable Future. Beacon Press, Boston.

Dworkin, R. (1981) What is equality? Part II: Equality of resources, Philosophy and Public Affairs 10.

Hare, R.M. (1952) The Language of Morals. Clarendon Press, Oxford.
Hare, R.M. (1963) Freedom and Reason. Clarendon Press, Oxford.

Klasen, S. (1994) Growth and well-being: Introducing distribution-weighted growth rates to reevaluate postwar economic performance, Review of Income and Wealth, Series 40 No. 3.

Marglin, S. A. (1990) Towards the decolonization of the mind. In Dominating Knowledge: Development, Culture, and Resistance, eds. F. A. Marglin and S. A. Marglin, Clarendon Press, Oxford.

Morris, M.D. (1979) Measuring the Condition of the World's Poor: The Physical Quality of Life Index. Frank Cass, London.

Nozick, R. (1974) Anarchy, State, and Utopia. Blackwell, Oxford.

Osmani, S. R. (1982) Economic Inequality and Group Welfare: A Theory of Comparison with Application to Bangladesh. Clarendon Press, Oxford.

Preston, R. (1986) Equality. In The Westminster Dictionary of Christian Ethics, eds. J. F. Childress and J. Macquarrie. Westminster Press, Philadelphia.

Rawls, J. (1971) A Theory of Justice. Harvard University Press, Cambridge, MA.

Sen, A. K. (1973) On Economic Inequality. Oxford University Press, London.

Sen, A. K. (1976) Poverty: An ordinal approach to measurement. Econometrica 44, 219-231.

Sen, A. K. (1980) Equality of what? In The Tanner Lectures on Human Values, Vol. 1, Cambridge University Press, Cambridge.

Sen, A. K. (1981) Public action and the quality of life in developing countries. Oxford Bulletin of Economics and Statistics 43(1). 287-319. 
Sen, A. K. (1983) Development: Which way now? Economic Joumal 93.

Sen, A. K. (1992) Inequality Reexamined. Harvard/Russell Sage, Cambridge. MA.

Sen, A. K. (1993) Capability and well-bcing, In The Quality of Life, eds. A. Sen and M. Nussbaum, Clarendon Press, Oxford.

Srinivasan, T.N. (1994) Human development: A new paradigm or reinvention of the wheel? American Economics Review 84(2), 238-243.

Streeten, P. (1994) Human development: Means and ends. American Economic Review 84(2), 232-237.

Streeten, P., Burki, S. J., Haq, M. ul, Hicks, N. and Stewart, F. (1981) First Things First: Meeting Basic Human Needs in the Developing Countries. Oxford UP for the World Bank, Oxford.

UNDP (1990) Human Development Report 1990. Oxford University Press, New York.

UNDP (1991) Human Development Report 1991. Oxford University Press, New York.
UNDP (1992) Human Development Report 1992. Oxford University Press, New York.

UNDP (1993) Human Development Report 1993. Oxford University Press, New York.

UNDP (1994) IIuman Development Report 1994. Oxford University Press, New York.

UNDP (1995) Human Development Report 1995. Oxford University Press, New York.

UNDP (1996) Human Development Report 1996. Oxford University Press, New York.

UNESCO (1995) UNESCO'95 Statistical Yearbook. Lanham, MD and Paris.

United Nations (1992) U.N. Demographic Yearbook 1992Special Topic: Fertility and Morbidity Statistics. United Nations, New York.

Williams, B. A. O. (1962) The idea of equality, In Philosophy, Politics and Society, eds. P. Laslett and W.G. Runciman, Second Series. Blackwell, Oxford.

World Bank (1995) World Development Report. Oxford University Press, New York. 